\title{
MORTALITY FROM BURN: AN AUTOPSY BASED STUDY FROM NEPAL
}

Madan Prasad Baral ${ }^{1^{*}}$, Sidarth Timsinha

\begin{abstract}
Affiliation
1. Assistant Professor, Department of Forensic Medicine, Pokhara Academy of Health Science, Pokhara, Nepal

2. Associate Professor, Department of Forensic Medicine, Birat Medical College and Teaching Hospital, Nepal
\end{abstract}

\section{ARTICLE INFO}

Received : 29 March, 2021

Accepted : 23 July, 2021

Published : 04 November 2021

(C) Authors retain copyright and grant the journal right of first publication with the work simultaneously licensed under Creative Commons Attribution License CC - BY 4.0 that allows others to share the work with an acknowledgment of the work's authorship and initial publication in this journal.

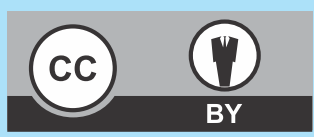

ORA 258

DOI: https://doi.org/10.3126/bjhs.v6i2.40333

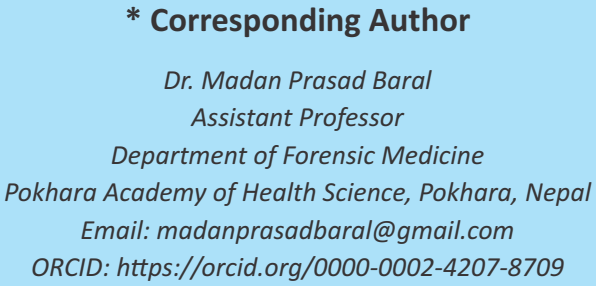

\section{Citation}

Madan Prasad Baral, Sidarth Timsinha. Mortality from Burn: an Autopsy Based Study from Nepal. BJHS 2021;6(2)15. 1496-1500.

\section{ABSTRACT \\ Introduction}

In developing countries like Nepal burn deaths are a major public health problem due to their increased mortality, morbidity and long-term disability. A few clinical studies on burns have been reported from Nepal however, autopsy based studies on burns are limited.

\section{Objectives}

To study the socio-demographic characteristics of victims of burns and evaluate the cause and magnitude of fatal burn injuries retrospectively.

\section{Methodology}

A two years retrospective analysis of burn deaths brought for autopsy was conducted from January 2017 to December 2018 in a central level hospital of Nepal.

\section{Result}

Out of 775 total cases autopsied 38 (4.90\%) cases were burn related deaths. The majority of the deaths $17(44.70 \%)$ occurred in the age group 21-30 years with a preponderance in females 22(57.89\%). Majority of the victims were married females $25(65.78 \%)$ and most of them were housewives 14(36.84\%). Flame burn 23(60.52\%) was the most common cause of all burns. The Total Body Surface Area (TBSA) Burn between $50-69 \%$ was observed in majority of the cases $27(71.05 \%)$. Most of the victims $15(39.47 \%)$ survived over 10 days post injury. Burn incidents were mainly accidental $33(86.84 \%)$ in nature followed by suicidal burns $5(13.15 \%)$. The main cause of burn death was septicemic shock $16(42.10 \%)$ followed by neurogenic shock $10(26.31 \%)$.

\section{Conclusion}

The results of this study show that burns injuries are mostly accidental in nature; therefore, the risks of burn injuries should be rightly addressed and appropriate burn prevention strategies should be developed to reduce the frequency and burn related deaths.

\section{KEYWORDS}

Accidental, Autopsy, Burn, Mortality, Septicemia 


\section{INTRODUCTION}

Burns are one of the highly destructive injuries, causing not only deaths but also major economic, psychological, and long-term consequences. ${ }^{1}$ There is around 300,000 deaths worldwide due to burns each year. Of these, 95\% happen in developing countries with Southeast Asia recording about $57 \%$ of deaths due to burns. ${ }^{2}$ The Annual Report from the Department of Health and Population for Nepal, including the fiscal year 2016-2017, recorded 55,090 burn or scald injuries nationally. ${ }^{3}$ A nation-wise household survey in 15 districts in Nepal reported an incidence of 55 burns from 1350 households. The majority of cases $(60.4 \%)$ were due to hot liquid and/or hot objects. ${ }^{4}$ Deaths from burns are normally accidental in nature however; it might be of suicidal or homicidal origin. Suicidal burning is relatively uncommon. Homicidal burning is unusual, yet it is found in situations where paraffin or some other inflammable material is thrown over victims and their apparel and then ignited. ${ }^{5}$ It is common for an offender to try to discard the body of the victim by the fireplace to hide the crime. At times, some people might cause burn injuries on a dead body and after ward produce it before the police to assist a misleading allegation of homicide against foe. In each case, care is to be taken to identify ante mortem and post mortem burns to point that victim was alive or not during fire. ${ }^{6}$ In Nepal few clinical studies on burns have been reported on burn victims however, autopsy based studies are limited..$^{7-9}$ In this region postmortem study of burn cases from a medicolegal viewpoint has not been conducted till date. Therefore, the present study is conducted to analyze the epidemiology, aetiology, causes and manner of death in autopsied burn cases in Morgue of Western Regional Hospital of Pokhara Academy of Health Sciences (PAHS) which is one of the central level hospitals in Nepal.

\section{METHODOLOGY}

A retrospective review of autopsy report on burn deaths from January 2017 to December 2018 was carried out at Western Regional Hospital of Pokhara Academy of Health Sciences (PAHS). The study was approved by the Hospital administration as institutional ethical committee. A total number of 775 cases were autopsied in morgue of Forensic medicine department during the study period. Out of these 38 cases were related to burns. The details of these 38 cases were collected and thoroughly reviewed. Data was related to corpse and not harmful for living human beings; privacy of data was maintained while collecting the data. The collected data included age, sex, marital status, percentage of burn, hospitalization and survival time, cause of death and manner of death. The Total Body Surface Area (TBSA) burn was estimated by the rule of nine for all the cases. Further the police inquest was also reviewed to gather additional information regarding crime scene and statements of relatives. All the information was noted in a pre-structured Pro forma. The data was then entered and analysed using Microsoft Excel 2014.

\section{RESULTS}

Table 1: Socio-demographic profile of victims

Age Group(years) No $(\%)$

\begin{tabular}{|l|r|}
\hline $0-10$ & $5(13.15 \%)$ \\
\hline $11-20$ & $7(18.42 \%)$ \\
\hline $21-30$ & $17(44.70 \%)$ \\
\hline $31-40$ & $3(7.89 \%)$ \\
\hline $41-50$ & $1(2.63 \%)$ \\
\hline $51-60$ & $2(5.26 \%)$ \\
\hline $61-70$ & $1(2.63 \%)$ \\
\hline $71-80$ & $2(5.26 \%)$ \\
\hline$>81$ & $0(0 \%)$ \\
\hline Gender & \\
\hline Male & $16(42.10 \%)$ \\
\hline Female & $22(57.89 \%)$ \\
\hline District & \\
\hline Kaski & $26(68.42 \%)$ \\
\hline Syanja & $9(23.68 \%)$ \\
\hline Others & $3(7.89 \%)$ \\
\hline Occupation & \\
\hline Farmers & $11(28.94 \%)$ \\
\hline Employed & $4(10.52 \%)$ \\
\hline Unemployed & $2(5.26 \%)$ \\
\hline Students & $5(13.15 \%)$ \\
\hline Manual workers & $2(5.26 \%)$ \\
\hline Housewives & $14(36.84 \%)$ \\
\hline Marital status & $25(65.78 \%)$ \\
\hline Married & $13(34.22 \%)$ \\
\hline Unmarried & \\
\hline
\end{tabular}

The present study comprised of 38 autopsy cases of burns out of total 775 autopsies conducted during the period of January 2017 to December 2019.The victims aged between 7 to 75 years with female preponderance 22(57.89\%). The male-female ratio was $1: 1.3$. Majority of cases reported from Kaski district 26(68.42\%) of Gandaki province when compared to other districts. Most of the subjects were married 25(65.78\%) and among them, 14(56.0\%) were housewives.

Table 2 shows that in majority 22(57.89\%) of cases total body surface area burn was between 50-69 \% with a higher incidence $16(42.10 \%)$ cases in the age group 21-30 years. Table 3 illustrates the relation between the percentage of TBSA burn and the period of survival. Out of 38 cases, $27(71.05 \%)$ cases suffered $50-69 \%$ TBSA burn. Only 2 (5.26\%) cases were brought dead cases with $70-79 \%$ TBSA burn. Out of 27 cases, 13 cases (28.93\%) survived for 1-8 days, 5 cases (13.15\%) survived for $9-10$ days and 9 (23.68\%) cases survived for more than 10 days post-injury. 
Table 2: Age group and extent of burn

\begin{tabular}{|l|c|c|c|c|c|c|r|}
\hline Age group & $<39 \%$ & $\mathbf{4 0 - 4 9 \%}$ & $\mathbf{5 0 - 5 9 \%}$ & $\mathbf{6 0 - 6 9 \%}$ & $\mathbf{7 0 - 7 9 \%}$ & $\mathbf{> 8 0 \%}$ & \multicolumn{1}{c|}{ Total (\%) } \\
\hline 010 & 3 & 0 & 0 & 0 & 0 & 0 & $3(7.89 \%)$ \\
\hline $11-20$ & 1 & 2 & 2 & 0 & 0 & 0 & $5(13.15 \%)$ \\
\hline $21-30$ & 1 & 4 & 5 & 6 & 0 & 0 & $16(42.10 \%)$ \\
\hline $31-40$ & 0 & 1 & 1 & 1 & 0 & 0 & $3(7.89 \%)$ \\
\hline $41-50$ & 0 & 1 & 0 & 1 & 1 & 0 & $3(7.89 \%)$ \\
\hline $51-60$ & 0 & 1 & 2 & 2 & 0 & 0 & $5(13.15 \%)$ \\
\hline $61-70$ & 0 & 0 & 1 & 0 & 1 & 0 & $2(5.26 \%)$ \\
\hline $71-80$ & 0 & 0 & 1 & 0 & 0 & 0 & $2(5.26 \%)$ \\
\hline$\geq 80$ & 0 & 0 & 0 & 0 & 0 & 0 & $0(0.00 \%)$ \\
\hline Total & 5 & 9 & 12 & 10 & 2 & 0 & $38(100.0 \%)$ \\
\hline
\end{tabular}

Table 3: Percentage of TBSA burn and period of survival

\begin{tabular}{|l|r|r|r|r|r|r|r|}
\hline \multirow{2}{*}{ Hospital stay } & \multicolumn{7}{|c|}{ Percentage of burns } \\
\cline { 2 - 7 } & $39 \%$ & $\mathbf{4 0 - 4 9 \%}$ & $\mathbf{5 0 - 5 9 \%}$ & $\mathbf{6 0 - 6 9 \%}$ & $\mathbf{7 0 - 7 9 \%}$ & $>\mathbf{8 0} \%$ & Total (\%) \\
\hline Brought dead & $0(0 \%)$ & $0(0 \%)$ & $0(0 \%)$ & $0(0 \%)$ & $2(5.26 \%)$ & $0(0 \%)$ & $2(5.26 \%)$ \\
\hline$<12$ hours & $0(0 \%)$ & $0(0 \%)$ & $0(0 \%)$ & $0(0 \%)$ & $0(0 \%)$ & $0(0 \%)$ & $0(0 \%)$ \\
\hline $12-24$ hours & $0(0 \%)$ & $0(0 \%)$ & $0(0 \%)$ & $0(0 \%)$ & $1(2.63 \%)$ & $0(0 \%)$ & $1(2.63 \%)$ \\
\hline $1-2$ days & $0(0 \%)$ & $0(0 \%)$ & $0(0 \%)$ & $2(5.26 \%)$ & $1(2.63 \%)$ & $0(0 \%)$ & $3(7.89 \%)$ \\
\hline $3-4$ days & $0(0 \%)$ & $0(0 \%)$ & $3(7.89 \%)$ & $1(2.63 \%)$ & $0(0 \%)$ & $0(0 \%)$ & $4(10.52 \%)$ \\
\hline $5-6$ days & $0(0 \%)$ & $0(0 \%)$ & $1(2.63 \%)$ & $1(2.63 \%)$ & $0(0 \%)$ & $0(0 \%)$ & $2(5.26 \%)$ \\
\hline $7-8$ days & $0(0 \%)$ & $0(0 \%)$ & $2(5.26 \%)$ & $3(7.89 \%)$ & $0(0 \%)$ & $0(0 \%)$ & $5(13.15 \%)$ \\
\hline $9-10$ days & $0(0 \%)$ & $1(2.63 \%)$ & $2(5.26 \%)$ & $3(7.89 \%)$ & $0(0 \%)$ & $0(0 \%)$ & $6(15.78 \%)$ \\
\hline$>10$ days & $1(2.63 \%)$ & $5(13.15 \%)$ & $5(13.15 \%)$ & $4(10.52 \%)$ & $0(0 \%)$ & $0(0 \%)$ & $15(39.47 \%)$ \\
\hline Total & $1(2.63 \%)$ & $6(15.78 \%)$ & $13(34.21 \%)$ & $14(36.84 \%)$ & $4(10.52 \%)$ & $0(0 \%)$ & $38(100 \%)$ \\
\hline
\end{tabular}

Table 4: Cause of burn

\begin{tabular}{|l|c|c|c|c|c|c|}
\hline Gender & Flame & Scalds & Electricity & Chemicals & Lightening & Total \\
\hline Male & $7(43.75 \%)$ & $3(18.75 \%)$ & $4(25.00 \%)$ & $1(6.25 \%)$ & $1(6.25 \%)$ & $16(100 \%)$ \\
\hline Female & $16(72.72 \%)$ & $3(13.63 \%)$ & $1(4.54 \%)$ & $1(4.54 \%)$ & $1(4.54 \%)$ & $22(100 \%)$ \\
\hline Total & $23(60.52 \%)$ & $6(15.78 \%)$ & $5(13.15 \%)$ & $2(5.26 \%)$ & $2(5.26 \%)$ & $38(100 \%)$ \\
\hline
\end{tabular}

Flame burn 23(60.52\%) was the most common cause of all burns followed by scalds 6(15.78\%) and electric burn 5(13.15\%). Flame burn affected more females 16 (72.72\%) than males7 (43.75\%) while electrical burn affected more males $4(25.00 \%)$ than females $1(4.54 \%)$. Scalds, lightening, and chemical burn affected both the sexes equally.

Table 5: Manner of death
\begin{tabular}{|l|c|c|r|}
\hline Manner & Male & Female & \multicolumn{1}{c|}{ No (\%) } \\
\hline Accidental & 15 & 18 & $33(86.84)$ \\
\hline Suicidal & 1 & 4 & $5(13.15)$ \\
\hline Homicidal & 0 & 0 & $0(0)$ \\
\hline Total & 16 & $\mathbf{2 2}$ & $\mathbf{3 8}(100)$ \\
\hline
\end{tabular}

In maximum cases, burns were accidental 33(86.84\%) in nature followed by suicidal burns $5(13.15 \%)$. Suicidal burns were more common in female $4(80.00 \%)$ than male $1(20.00 \%)$. We did not find any case of homicidal burn in this study. Septicemia 16(42.10\%) was the major cause of burn death in our study.

As per history, dying declaration of victim (ante mortem), police investigations and post-mortem report, it was observed that in majority of the burn victims, the manner of burn was accidental. 
Table 6: Cause of death

\begin{tabular}{|c|c|c|c|c|c|c|}
\hline Cause & Flame & Scalds & Electricity & Chemicals & Lightening & Total \\
\hline Neurogenic & 2 & 1 & 4 & 1 & 2 & $10(26.31 \%)$ \\
\hline Hypovolemic shock & 4 & 3 & 0 & 0 & 0 & $7(18.42 \%)$ \\
\hline Septicemia & 13 & 2 & 1 & 0 & 0 & $16(42.10 \%)$ \\
\hline Bronchopneumonia & 3 & 0 & 0 & 1 & 0 & $4(10.52 \%)$ \\
\hline Multi organ failure & 1 & 0 & 0 & 0 & 0 & $1(2.63 \%)$ \\
\hline Total & 23 & 6 & 5 & 2 & 2 & $38(100)$ \\
\hline
\end{tabular}

\section{DISCUSSION}

In this study, the age group 21-30 years (44.7\%) was mainly involved in burns. Chakraborty Set $\mathrm{al}^{10}$ also observed majority of the burn victims in the age group of 20-39 years $(56.6 \%)$. This finding is also comparable to an Indian study in which (59.6\%) of burn victims were between 15-30 years. ${ }^{11}$ This age group is both productive and active in terms of earning a living, which exposes individuals to a variety of injuries, including burns. Our study showed that burns were common in females $(57.89 \%)$ than males $(42.10 \%)$. Also, burns were observed more in married females (65.78\%) and among housewives (56.0\%). Our finding is in agreement to a study conducted in Nepal, where burns were common in females accounting $79 \%$ and among married females $84 \% .{ }^{12}$ LiuE Het al also observed burns common in females (52.8\%) than males $(47.2 \%){ }^{13}$ In contrast burns were more in males $(58.0 \%)$ than females $(42.0 \%)$ with male: female ratio of 1.3:1 in a Nepalese study. ${ }^{14}$ The female preponderance is perhaps because females are regularly exposed to fire sources as they cook on regular basis as compared to males especially after marriage. In our study maximum cases reported from Kaski district (68.42\%) of Gandaki Province of Nepal. Our study site is located in same district and it is most established and largest one thereby covering large number of cases. It is very certain that the deaths are directly proportional to percentage of burns. In the present study, majority of the subjects sustained over 50\% TBSA burn with mortality rate of $(57.89 \%)$. This indicates the incompatibility with life even at a tertiary care centre. In a study from Angola ${ }^{15}$ majority of the victims sustained over $40 \%$ TBSA burn with (100\%) mortality. Similarly, over $40-50 \%$ TBSA burn has been reported from other studies with $(80 \%)$ mortality rate. ${ }^{16,17}$ In our study, flame burn accounted for $(60.52 \%)$ of burns. Similar, findings were observed in a Nepalese study where flame burn (64\%) was the main cause of burn injuries. ${ }^{7}$ However, Poudel K et ${ }^{18}$ al observed burns due to contact with hot liquid and steam (53\%) was the most common cause of burns followed by open fires and flames (36\%).In the same way, Gupta S et $a^{19}$ found that $60.4 \%$ of burns were caused by hot liquids and/or hot objects, while $39.6 \%$ were caused by an open fire or explosion. The majority of Nepalese people are unaware of burn safety precautions, and cooking is still done over traditional open fire. Housewives are more likely to come into contact with fire while cooking, especially in small and crowded houses. This indicates the presence of social problems among married females, who have all household responsibilities even in urban setting like ours. Another element that may contribute to burn incidents among females is the loose flammable clothes they wear like sari and shawls that can easily catch fire exposing them to burn injuries. In the current study, maximum (28.93\%) cases died within a week after hospitalization, indicating that burns are highly fatal. Vilasco $\mathrm{B}$ and Bondurand $\mathrm{A}^{20}$ reported $(40 \%)$ burn deaths between 3 and 7 days of the incident. Correspondingly, Kumar $V$ et al $^{21}$ also reported death from burns within a week in $(60.8 \%)$ victims. In this study, soot particles were found in trachea in $(18.42 \%)$ cases. Similar findings where soot particles in trachea was noticeable in (18.05\%) cases was reported in an Indian study. ${ }^{22}$ Almost, all the victims in our study died in the hospital after receiving treatment. This could be the reason of absence of soot particles in the trachea. It is very challenging to opine that a burn injury is accidental, suicidal or homicidal in nature. According to history, dying declaration, police investigations and postmortem report (86.84\%) of deaths in our study was due to accidental burns. Similar observation was made by Vidhate SG et $\mathrm{al}^{23}$ where, majority (65.14\%) of deaths were due to accidental burns. Chakraborty $S$ et al ${ }^{10}$ also reported in his study that out of 83 cases most of the cases were due to accidental burns (61.4\%). This might be due to regular contact with fire and kerosene while cooking, as well as a lack of awareness of burn safety measures among females. In most of the cases the common cause of death was septicaemia (42.10\%). This finding is comparable with an Indian study where majority of death $(55 \%)$ was due to septicaemia. ${ }^{24}$ Also, in a study on 352 patients with burns, septicaemia was the leading cause of death in 10 patients out of 16 fatalities. ${ }^{25}$

\section{CONCLUSION}

The epidemiological components for burn injuries vary from country to country. In present study more than half of the victims died were married women who were actively involved in house hold activity including cooking. Accidental burn occurred in most of the cases with just a few cases being suicidal in nature. In the current study, there was no 
incidence of homicidal burns. Septicemia was the leading cause of death among burn victims.

\section{RECOMMENDATION}

As majority of burn incidence occurred from preventable causes, it is imperative to educate the common people about burns prevention and safety measures. Creating awareness in the family especially the housewives and parents and also in male concerning risk in work locations, would be certainly productive. Also, setting regulations to develop safer cooking appliances, promoting less inflammable fabrics to be worn at home and educating the community especially women on safer first aid practices would be highly beneficial. Therefore, married female housewives can be the target group for awareness regarding safety measure for burn injury to reduce the number of burn injury cases in future from this particular region of Gandaki Province Nepal.

\section{LIMITATIONS OF THE STUDY}

This study was conducted in a single location. There are other districts in Gandaki Province where autopsies are performed, so the current study cannot reflect the actual burden of burn deaths from Kaski district despite the fact the current location is a tertiary centre where complicated burn cases are referred from other districts.

\section{ACKNOWLEDGEMENTS}

We would like to thank the supporting staffs of Medical Record Department (MRD), Department of Forensic medicine of Western Regional Hospital of Pokhara Academy Of Health Sciences (PAHS) for their kind support.

\section{CONFLICT OF INTEREST}

None

\section{FINANCIAL DISCLOSURE}

None

\section{REFERENCES}

1. Sadeghi BH, Maghsoudi $H$, Soudmand NM, Ranjbar F, Mashadi AH. Stress disorder and PTSD after burn injuries: a prospective study of predictors of PTSD at Sina Burn Center, Iran. Neuropsychiatr Dis Treat 2011; 7:425-9. PMID: 21857783

2. World Health Organization (WHO). A WHO Plan for Burn Prevention and Care. Geneva: WHO, 2008. Available from: http:// whqlibdoc. who.int/publications/2008/9789241596299_eng.pdf.

3. Ministry of Health and Population. Annual report, 2016. Kathmandu Nepal: Department of Health Services, 2016/17.

4. Tripathee S, Basnet SJ. Erratum to: Epidemiology of burn injuries in Nepal: a systemic review: a systemic review. Burns Trauma 2017; 5(15). PMID: 28413803

5. Mukherjee JB. Forensic Medicine and Toxicology.2nd ed. New Delhi:1994 p. 440-454

6. Saukko P, Knight B. Knights forensic pathology. 3rd ed. London: Arnold, 2004 p.12-325.

7. DahalP, Paudal BR. Pattern of Burn patients admitted in a Burn Unit of Bir Hospital Kathmandu. Post Graduate Med J NatlAcad Med Sci 2010; 10(2):62-4.

8. Karki B, Rai SM, Nakarmi KK, Basnet SJ, Magar MG, Nagarkoti KK. Clinical Epidemiology of Acute Burn Injuries at Nepal Cleft and Burn Centre, Kathmandu, Nepal. Ann PlastSurg 2018; 80(3):S95-S97. PMID: 29319567

9. Rai SM, Karki B, Nakarmi K, Ghartimagar M, Nagarkoti K, Joshi KD. Retrospective study on early outcome of acute burn injuries treated at Nepal Cleft and Burn Centre of Public Health Concern Trust-Nepal. J Nepal Health Res Counc 2014; 12(28):195-9. PMID: 26032059.

10. Chakraborty S, Bisoi S, Chattopadhyay D, Mishra R, Bhattacharya N, Biswas B. A study on demographic and clinical profile of burn patients in an Apex Institute of West Bengal. Indian J Public Health 2010; 54(1):27-9. PMID: 20859047

11. Gupta R, Kumar V, Tripathi S. Profile of the fatal burn deaths from the varanasi region, India. J Clin and Diag Res 2012; 6(4):608-611.

12. Lama BB, Duke JM, Sharma NP, Thapa B, DahalP,Bariya ND. Intentional burns in Nepal: a comparative study. Burns 2015;41(6):1306-14. PMID: 25716765
13. Liu EH, Khatri B, Shakya YM, Richard BM. A 3 year prospective audit of burns patients treated at the Western Regional Hospital of Nepal. Burns 1998; 24(2):129-33.PMID: 9625237

14. Chalise PR, Shrestha S, Sherpa K, Nepal U, Bhattachan CL. Epidemiological and bacteriological profile of burn patients at Nepal Medical College Teaching Hospital. Nepal Med Coll J 2008; 10(4):233-7.PMID: 19558060

15. Adamo C, Esposito G, Lissia M, Vonella M, Zagaria N, Scuderi N. Epidemiological data on burn injuries in Angola: a retrospective study of 7230 patients. Burns 1995; 21(7):536-8. PMID: 8540983

16. Virendra K, Manoj KM, Sarita K. Fatal burns in Manipal area: a 10 year study. J Forensic Leg Med 2007;14(1):3-6. PMID: 17046310

17. Gupta M, Gupta OK, Yaduvanshi RK, Upadhyaya J. Burn epidemiology in Pink city scene. Burns 1993; 19(1):47-51.PMID: 8435115

18. Poudel-Tandukar K, Nakahara S, Ichikawa M, Poudel KC, Joshi AB, Wakai S. Unintentional injuries among school adolescents in Kathmandu, Nepal: a descriptive study. Public Health 2006;120(7): 641-9.PMID: 16759678

19. Gupta S, Mahmood U, Gurung S, Shrestha S, Kushner AL, Nwomeh BC Burns in Nepal: a population based national assessment. Burns 2015; 41(5): 1126-32.PMID: 2552308

20. Vilasco B, Bondurand A. Burns in Abidjan Cote D'Ivoire. Burns 1995;21(4):291-6. PMID: 7662131

21. Kumar V, Mohanty MK, Kanth S. Fatal burns in Manipal area: a 10 year study. J Forensic Leg Med. 2007;14(1):3-6. PMID: 17046310.

22. Mazumdar A, Patowary A. A Study of Pattern of Burn Injury Cases. J Indian Acad Forensic Med, 2013,35(1):44-46.

23. VidhateSG,Pathak H. A study of medico-legal aspects of death due to burns at a tertiary care centre in Mumbai, India. Egypt J Forensic Sci2017;7(21):1-5.https://doi.org/10.1186/s41935-017-0018-6

24. Ramakrishnan KM, Sankar J, Venkatraman J. Profile of paediatric burns Indian experience in a tertiary care burn unit. Burns 2005; 31(3):3513. PMID: 15774293

25. Ho WS, Ying SY, Burd A. Outcome analysis of 286 severely burned patients: retrospective study. Hong Kong Med J 2002;8(4):235-9. PMID: 12167725 